\title{
Application of Chaos Theory in Trucks' Overloading Enforcement
}

\author{
Abbas Mahmoudabadi, ${ }^{1}$ and Arezoo Abolghasem ${ }^{2}$ \\ ${ }^{1}$ Department of Industrial Engineering, Payame Noor University (PNU), Shahnaz Alley, Nourian Street, North Dibagi Avenue, \\ Tehran, Iran \\ ${ }^{2}$ Road Maintenance and Transportation Organization, Number 12 Dameshq Street, Vali-e-Asr Avenue, Tehran, Iran \\ Correspondence should be addressed to Abbas Mahmoudabadi; mahmoudabadi@phd.pnu.ac.ir
}

Received 14 August 2012; Accepted 30 October 2012

Academic Editor: Sang-Min Han

Copyright (C) 2013 A. Mahmoudabadi and A. Abolghasem. This is an open access article distributed under the Creative Commons Attribution License, which permits unrestricted use, distribution, and reproduction in any medium, provided the original work is properly cited.

\begin{abstract}
Trucks' overloading is considered as one of the most substantial concerns in road transport due to a possible road surface damage, as well as, are less reliable performance of trucks' braking system. Sufficient human resource and adequate time scheduling are to be planned for surveying trucks' overloading; hence, it seems required to prepare an all-around model to be able to predict the number of overloaded vehicles. In the present research work, the concept of chaos theory has been utilized to predict the ratio of trucks which might be guessed overloaded. The largest Lyapunov exponent is utilized to determine the presence of chaos using experimental data and concluded that the ratio of overloaded trucks reflects chaotic behavior. The prediction based on chaos theory is compared with the results of simple smoothing and moving average methods according to the well-known criterion of mean square errors. The results have also revealed that the chaotic prediction model would act more capably comparing the analogous methods including simple smoothing and moving average to predict the ratio of passing trucks to be possibly overloaded.
\end{abstract}

\section{Introduction}

Road transportation is a dominant mode of freight transportation in Iran that accounts for about $80 \%$ of the freight movement [1]. The number of heavy vehicles is continuously increasing on the road network. Overloading is growing up, and it is a major cause for significantly accelerating the rate of pavement deterioration [2]. In addition to damage road surface, overloaded trucks endanger other vehicles because of predesigning of vehicles' braking systems particularly in curves and slopes. Having promoted road safety and minimizing road maintenance costs, ordinary road measures imposed on road pavement by axles' load of trucks are made as part of the enforcement process laws [3] is legally controlled by weighing stations.

Relevant studies in the field of pavement designs based on truck axle loads are referred in the literature. Turochy et al. [4] developed truck factors for pavement design and axle load distribution models for mechanistic-empirical pavement design using information from weigh-in-motion sites on arterial roads in Alabama. Till also developed a detailed method of wheel load modeling from overload trucks for bridge decks [5]. Chia-pei calculated average load factors for combined heavy vehicles and axle load ratios for various types of heavy vehicles, to design bridge standard specification [6].

Although some location allocation techniques can be utilized to improve the efficiency of overloading enforcement [7], in order to minimize overloading, scheduling human resources who are employed staff in the process of checking trucks' axles load in weighing stations should be considered in road enforcement. Improving the efficiency, human resources scheduling would require the utilization of prediction methods. Recent techniques of prediction are observed in the literature by applying chaos theory in the field of road traffic. Frazier and Kockelman analyzed traffic flow data and found it chaotic. Their studies showed that predictions based on chaos theory would have greater predictive power than a nonlinear least-squares method [8]. Disbro and Frame demonstrated how the theoretically derived Gazis-HermanRothery traffic model [9] is highly chaotic, even though 
applied to medium or smaller (eight-car) systems [10]. Van Zuylen et al. discussed the implications of human behavior, chaos, and unpredictability for urban and transportation planning as well as forecasting [11].

Safonov et al. showed that chaotic behavior in traffic can be caused by delays in human reaction [12]. Nair et al. analyzed traffic flow data and characterized it as a chaotic factor [13]. Weidlich demonstrated how random-utilitybased models of relatively simple social behaviors produced chaotic behavior and offer a detailed application of chaos to traffic flow [14]. Metghalchia et al. examined the profitability of several simple technical trading rules for 16 European stock markets over the 1990 to 2006 period and concluded that increasing trend of moving average rules has predictive power being able to discern recurring price patterns for profitable trading, even after accounting for the effects of data snooping bias [15].

Four methodologies of predicting gas turbine behavior over time have also been utilized by Cavarzere and Venturini [16]. They are used to provide a time prediction when a threshold value will be exceeded in the future. Results presented an aim to select the most suitable methodology that allows both trending and forecasting as a function of data trend over time, in order to predict time evolution of gas turbine characteristic parameters and to provide an estimate of the occurrence of a failure [16].

The main contribution of this paper is to predict the ratio of overloaded trucks based on the concept of chaos theory. Following introduction, some methods of vehicles' axle loads controlling and the well-known prediction methods are briefly presented in the second and third sections, followed by the description of case study. Analytical process includes checking the presence of chaos behaviors using experimental data, as presented in the fifth section together with comparing results consisting of more discussions on the revealed results. A brief discussion of the applied process and some recommendations for further studies are also discussed in the last section.

\section{Goods Transportation Controlling and Trucks Axle Load}

Pavement management is an important issue, according to its maintenance and repairing roads surface expenses. Heavy vehicles' axle loads are understood as the most important factor of road destruction. Based on observed researches in the literature, the damage on roads surface is related to the vehicles' axle loads by a nonlinear acceleration rate mainly in a polynomial equation of forth degree [2]. Truck weighing control is made by certain equipments, incorporating static, dynamic, and portable scales. Different axle loads and limitations in the scope of case study are shown in Table 1 including three most popular axle group configurations. They include 3 axle-10 wheels, 5 axle-12 wheels, and 5 axle-18 wheels trucks. Maximum axle loads are different from different configurations; however, it does not seem necessary if the total weigh is equal to the sum of axle load limitations. Trucks' axle loads are checked in weighing stations by random and if they exceed the authorized limit, overloaded trucks would
TABLE 1: Axle group configurations and weight limitations of most popular trucks.

\begin{tabular}{|c|c|c|c|c|}
\hline \multirow{2}{*}{ Axle group configuration } & \multicolumn{4}{|c|}{ Weight limitation (Ton) } \\
\hline & A & $\mathrm{B}$ & $\mathrm{C}$ & $A+B+C$ \\
\hline $\begin{array}{llll}\mathrm{C} & & \\
\mathrm{A}_{2} & & \mathrm{~B}_{8} \\
\mathrm{~A}_{2} & & \end{array}$ & 6 & 22 & - & 28 \\
\hline $\begin{array}{ccc}\mathrm{C} & & \\
\mathrm{A}_{2} & \mathrm{~B}_{4} & \mathrm{OOOO} \\
\mathrm{C}_{6}\end{array}$ & 6 & 13 & 24 & 42 \\
\hline $\begin{array}{lll}\mathrm{C}_{\mathrm{O}}=\mathrm{O}=\mathrm{O} & \\
\mathrm{A}_{2} & \mathrm{~B}_{8} & \mathrm{C}_{8}\end{array}$ & 6 & 22 & 22 & 44 \\
\hline
\end{tabular}

be stopped afterwards, requiring the loads adjusted based on regulations.

\section{Time Series Prediction}

3.1. Moving Average. Moving average method of prediction is obtained by first taking the average of the first subset. The fixed subset size is then shifted forward, creating a new subset of numbers, which is averaged [17]. Equation (1) shows the overall definition of moving average method where $P_{n+t+1}$ is the predicted amount for $n+t+1$ based on the previous amounts of real demands, and $n$ is the period. Using moving average technique is observed in the literature while Narasimhan et al. proposed new prediction techniques for MPEG-4 encoded variable bit rate video traffic based on the concept of moving average and extension further using the gradient-descent approach [18]:

$$
P_{t+n+1}=\frac{\left(X_{t+1}+X_{t+2}+\cdots+X_{t+n}\right)}{n} .
$$

3.2. Exponential Smoothing. Exponential smoothing is either applied to time series data, or to produce smoothing data, for which the time series are sequence of observations. Raw data sequence is often represented by $\left\{X_{t}\right\}$, and the output of the exponential smoothing algorithm is written as $\left\{P_{t}\right\}$, to be regarded as the best estimate of what the next value of $\mathrm{X}$. When the sequence of observations begins at time $t=0$, the most simple form of exponential smoothing is given by (2) [17] where $\alpha$ is the smoothing factor, and $0<$ $\alpha<1$. Snyder et al. used exponential smoothing method in sales forecasting for inventory control that has always been rationalized in terms of statistical models that possess errors with constant variances. It is shown that exponential smoothing remains appropriate under more general conditions, where the variance is allowed to grow or contract with corresponding movements in the underlying level [19]:

$$
P_{1}=X_{0}, \quad P_{t+1}=\alpha \times X_{t}+(1-\alpha) \times P_{t}, \quad t>1 .
$$

\section{Case Study and Experimental Data}

Experimental data of trucks' axle load have been stored using weigh in motion (WIM) system installed in highways. WIMs are fully automated systems which record all vehicles 
TABLE 2: Coefficients and mean square errors in chaos and simple exponential smoothing.

\begin{tabular}{|c|c|c|c|c|c|c|c|}
\hline \multirow[b]{2}{*}{ Axle configuration } & \multicolumn{2}{|l|}{ Method } & \multicolumn{2}{|c|}{ Simple exponential smoothing } & \multicolumn{3}{|c|}{ Chaos theory $(\Delta t=1)$} \\
\hline & Number of vehicles & Overload & $\alpha_{\text {best }}$ & MSE & $\lambda_{\max }$ & $\beta_{\text {best }}$ & MSE \\
\hline \multirow{2}{*}{3 axle 10 wheel } & \multirow{2}{*}{12898} & Axle & 0.56 & 0.0017 & 0.1769 & 1.3183 & 0.0016 \\
\hline & & Total & 0.52 & 0.0021 & 0.2018 & 1.3528 & 0.0021 \\
\hline \multirow{2}{*}{5 axle 12 wheel } & \multirow{2}{*}{4211} & Axle & 0.24 & 0.0030 & 0.2176 & 1.5065 & 0.0026 \\
\hline & & Total & 0.39 & 0.0022 & 0.0917 & 1.1045 & 0.0024 \\
\hline \multirow{2}{*}{5 axle 18 wheel } & \multirow{2}{*}{25525} & Axle & 0.71 & $\approx 0$ & 0.0289 & 1.0051 & $\approx 0$ \\
\hline & & Total & $\approx 1$ & 0.0004 & 0.0957 & 1.1360 & 0.0003 \\
\hline \multirow{2}{*}{ Total } & \multirow{2}{*}{42634} & Axle & 0.67 & 0.0004 & 0.3186 & 2.9942 & 0.0003 \\
\hline & & Total & 0.82 & 0.0008 & 0.2600 & 0.8735 & 0.0004 \\
\hline
\end{tabular}

and capable of measuring at normal traffic speed, without necessary to stop vehicles or drive at low speed, making them more efficient [20]. Vehicles passing through the sensors connected to a digital video camera system are detected while data are stored simultaneously. Experimental data have been collected by weigh in motion system in Arak-Qom highway and used to analyze in one month period. Three kinds of trucks including 3 axles 10 wheels, 5 axles 12 wheels and 5 axles 18 wheels have been selected for data analyzing because of high frequency of trucks' volume.

\section{Analytical Process}

After checking the presence of chaos, analytical process has been done based on two methods of time series prediction and the concept of chaos theory. Simple exponential smoothing is corresponding to the chaos theory with time span 1 day, and moving average method corresponding to the chaos theory considering time spans 3,5 , and 7 days as well as data for 42634 vehicles' axle loads that are collected during the time period of case study.

5.1. Presence of Chaos. A more common technique to determine the presence of chaotic behavior is calculating the largest Lyapunov exponent. Equation (3) determines the largest Lyapunov exponent where $S(t)$ is the observation in $t, S^{\prime}(t)$ is its nearest neighbor, and $N$ is the number of observations. When the largest Lyapunov exponent exceeds 0 , the system is chaotic [21]:

$$
\lambda_{\max }=\frac{1}{N \Delta t} \sum_{t=0}^{N-1} \operatorname{Ln}\left(\frac{\left|S(t+\Delta t)-S^{\prime}(t-\Delta t)\right|}{\left|S(t)-S^{\prime}(t)\right|}\right) .
$$

The ratio of vehicles which are suspicious to be overloaded comparing to passing vehicles is considered as a chaos factor in open interval $(01)$. Time span is considered as 24 hours, and data for 30 days were gathered. Eventually the well-known equation of logistic map [22] is utilized to define the ration of overloaded vehicles because of reasonable adaptation to traffic behaviors. Equation (4) defines the logistic map [23], where $P(t)$ is the ratio of trucks to be possibly overloaded:

$$
P(t+1)=\beta \times P(t) \times(1-P(t)) .
$$

5.2. Chaos Theory versus Simple Exponential Smoothing. Analytical process has been done for three types of most popular axle configurations while the numbers of trucks which are checked are different. Because of the same period of analyzing, simple exponential smoothing is compared with chaos theory using $(\Delta t=1)$. In regard to (2) and (3) two coefficients of $\alpha$ and $\beta$ need to be estimated minimizing mean square errors are notated as $\alpha_{\text {best }}$ and $\beta_{\text {best }}$ in Table 2. For each type of trucks, parameters have been estimated separately. Results shown in Table 2 revealed that the mean square error criterion of prediction corresponding to chaos is equal or less than one for simple exponential smoothing.

5.3. Chaos Theory versus Moving Average Method. Because of considering the same selected periods, moving average method is compared with chaos theory using $(\Delta t=3$, 5 and 7). Coefficients $\alpha$ and $\beta$ defined in (2) and (3) are estimated, regarding the minimum mean square errors in similar duration notated as $\alpha_{\text {best }}$ and $\beta_{\text {best }}$ in Tables 3 and 4. As it can be observed in Tables 3 and 4, readers are supposed to mention that the concept of chaos theory is more powerful technique for predicting ratio of trucks to be possibly overloaded because of the existing of chaotic behavior in overloading. It must be strictly mentioned that each time span is required to be compared with the same time span. So the results of situation $\Delta t=3,5,7$ must be compared with moving average method of $N=3,5$ and 7, respectively.

\section{Summary and Conclusion}

In this research work, the concept of chaos theory has been applied to predict the ratio of trucks likely to be overloaded in order to make an appropriate time table of human resources in vehicles' axle loads control. Data gathered in one-month period in the case study have been used for analytical process. Validation is checked by the results of two well-known methods of simple exponential smoothing and moving average time series.

Prediction analyses have been presented based on different time intervals including one, three, five, and seven days corresponding to the validation process and method of prediction. The mean square error, most popular criterion of prediction validity, is used to check the validity of proposed method. Discussing results showed that the prediction based 
TABLE 3: Coefficients and mean square errors in chaos theory.

\begin{tabular}{|c|c|c|c|c|c|c|c|}
\hline \multicolumn{2}{|c|}{ Method } & \multicolumn{6}{|c|}{ Chaos theory } \\
\hline \multirow[b]{2}{*}{ Axle configuration } & \multirow[b]{2}{*}{ Overload } & \multicolumn{2}{|c|}{$\Delta t=3$} & \multicolumn{2}{|c|}{$\Delta t=5$} & \multicolumn{2}{|c|}{$\Delta t=7$} \\
\hline & & $\beta_{\text {best }}$ & MSE & $\beta_{\text {best }}$ & MSE & $\beta_{\text {best }}$ & MSE \\
\hline \multirow{2}{*}{3 axle 10 wheel } & Axle & 1.3259 & 0.0025 & 1.3241 & 0.0002 & 1.3067 & 0.0002 \\
\hline & Total & 1.3699 & 0.0028 & 1.3854 & 0.0035 & 1.3472 & 0.0003 \\
\hline \multirow{2}{*}{5 axle 12 wheel } & Axle & 1.5080 & 0.0038 & 1.5161 & 0.0009 & 1.5005 & 0.0009 \\
\hline & Total & 1.0546 & 0.0040 & 1.0663 & 0.0038 & 1.1784 & $\approx 0$ \\
\hline \multirow{2}{*}{5 axle 18 wheel } & Axle & 0.9802 & $\approx 0$ & 1.0358 & $\approx 0$ & 1.0342 & $\approx 0$ \\
\hline & Total & 1.1300 & 0.0011 & 1.1386 & 0.0014 & 1.1339 & $\approx 0$ \\
\hline \multirow{2}{*}{ Total } & Axle & 1.1404 & 0.0007 & 1.1481 & $\approx 0$ & 1.4119 & $\approx 0$ \\
\hline & Total & 1.2040 & 0.0016 & 1.2141 & 0.0020 & 1.1951 & $\approx 0$ \\
\hline
\end{tabular}

TABLE 4: Coefficients and mean square errors in moving average.

\begin{tabular}{lcccc}
\hline \multirow{2}{*}{ Method } & & \multicolumn{3}{c}{ Moving average method } \\
& & $N=3$ & $N=5$ & $N=7$ \\
Axle configuration & Overload & MSE & MSE & MSE \\
\hline \multirow{2}{*}{ 3 axle 10 wheel } & Axle & 0.0021 & 0.0022 & 0.0025 \\
& Total & 0.0024 & 0.0027 & 0.0030 \\
\hline \multirow{2}{*}{5 axle 12 wheel } & Axle & 0.0039 & 0.0041 & 0.0044 \\
& Total & 0.0029 & 0.0030 & 0.0036 \\
\hline \multirow{2}{*}{5 axle 18 wheel } & Axle & $\approx 0$ & $\approx 0$ & $\approx 0$ \\
& Total & 0.0007 & 0.0008 & 0.0011 \\
\hline \multirow{2}{*}{ Total } & Axle & 0.0005 & 0.0006 & 0.0006 \\
& Total & 0.0010 & 0.0013 & 0.0016 \\
\hline
\end{tabular}

on the concept of chaos theory using logistic map equation is more capable than simple exponential smoothing and moving average time series methods. It has been shown, of course, more capable than simple exponential method of prediction when time interval is 1 day (next day), in respect, more powerful than moving average method if time intervals are 3, 5, and 7 days. In brief, chaos theory performs deeply better to predict the ratio of vehicles which are possibly overloaded rather than the other methods of prediction. Having interested to study in due field, it is recommended to focus on the application of chaos theory in the other road traffic measures to disclose which measures are able to be defined based on chaotic behavior.

\section{References}

[1] Road Maintenance and Transportation Organization, "Annual survey of road transport in Iran,” 1388 local calender, 2009, http://www.rmto.ir/NewTTO/MainF.asp/.

[2] A. Mahmoudabadi and A. Abolghasem, "A cluster-based method for evaluation of truck's weighing control stations," in MATLAB-A Ubiquitous Tool for the Practical Engineer, C. M. Ionescu, Ed., 2011.

[3] A. M. Asa, "Laws and regulations in rural transport," Road maintenance and transportation organization, 1378 local calendar, 1999.
[4] R. E. Turochy, D. H. Timm, and S. M. Tisdale, "Truck equivalency factors, load spectra modeling and effects on pavement design,” Tech. Rep. 930-564, Harbert Engineering Center, 2005.

[5] R. D. Till, "Overload truck wheel load distribution on bridge decks," Research Report R-1529, Michigan Transportation Commission, Structural Section Construction and Technology Division, 2009.

[6] C. J. Chia-pei, "Effect of overloaded heavy vehicles on pavement and bridge design," Transportation Research Board of the National Academies, no. 1539, pp. 58-65, 2007.

[7] A. Mahmoudabadi and S. M. Seyedhosseini, "Improving the efficiency of weigh in motion systems through optimized allocating truck checking oriented procedure," IATSS Research. In Press.

[8] C. Frazier and K. M. Kockelman, "Chaos theory and transportation systems: instructive example," in Proceedings of the 83rd Annual Meeting of the Transportation Research Board, Washington, DC, USA, January 2004.

[9] D. C. Gazis, R. Herman, and R. W. Rothery, "Nonlinear followthe-leader models for trafficflow," Operations Research, vol. 9, no. 4, pp. 545-567, 1961.

[10] J.E. Disbro and M. Frame, "Traffic flow theory and chaotic behavior," Transportation Research Record 1225, National Research Council, Washington, DC, USA, 1989.

[11] H. J. van Zuylen, M. S. van Geenhuizen, and P. Nijkamp, "(Un)predictability in traffic and transport decision making," Transportation Research Record 1685, National Research Council, Washington, DC, USA, 1999.

[12] L. A. Safonov, E. Tomer, V. V. Strygin, Y. Ashkenazy, and S. Havlin, "Delay-induced chaos with multifractal attractor in a traffic flow model," Europhysics Letters, vol. 57, no. 2, pp. 151-157, 2002.

[13] A. S. Nair, Liu Jyh-Charn, L. Rilett, and S. Gupta, "Nonlinear analysis of traffic flow," 2001, http://translink.tamu.edu/ docs/Research/LinearAnalysisTrafficFlow/chaos1.pdf/.

[14] W. Weidlich, Socio Dynamics: A Systematic Approach to Mathematical Modeling in the Social Sciences, Harwood Academic, Amsterdam, The Netherlands, 2000.

[15] M. Metghalchia, J. Marcucci, and Y.-H. Chang, "Are moving average trading rules profitable? evidence from the European stock markets," Applied Economics, vol. 44, no. 12, pp. 1539-1559, 2012.

[16] A. Cavarzere and M. Venturini, "Application of forecasting methodologies to predict gas turbine behavior over time," 
Journal of Engineering for Gas Turbines and Power, vol. 134, no. 1, Article ID 012401, 2012.

[17] B. R. Goodell, Smoothing Forecasting and Prediction of Discrete Time Series, Prentice-Hall, Englewood Cliffs, NJ, USA, 1963.

[18] H. Narasimhan, R. Tripuraribhatla, and K. S. Easwarakumar, "Moving average based predictors for MPEG-4 VBR traffic sources," in Proceedings of the IEEE Globecom Workshops (GC '10), pp. 924-928, Miami, Fla, USA, December 2010.

[19] R. D. Snyder, A. B. Koehler, and J. K. Ord, "Forecasting for inventory control with exponential smoothing," International Journal of Forecasting, vol. 18, no. 1, pp. 5-18, 2002.

[20] B. Jacob and V. F. L. Beaumelle, "Improving truck safety: potential of weigh-in-motion technology," IATSS Research, vol. 34, no. 1, pp. 9-15, 2010.

[21] C. Frazier and K. M. Kockelman, "Chaos theory and transportation systems: instructive example," Journal of the Transportation Research Record, no. 1897, pp. 9-17, TRB, National Research Council, Washington, DC, USA, 2004.

[22] S. C. Lo and H. J. Cho, "Chaos and control of discrete dynamic traffic model," Journal of the Franklin Institute, vol. 342, no. 7, pp. 839-851, 2005.

[23] J. Mingjun and T. Huanwen, "Application of chaos in simulated annealing," Chaos, Solitons and Fractals, vol. 21, no. 4, pp. 933-941, 2004. 

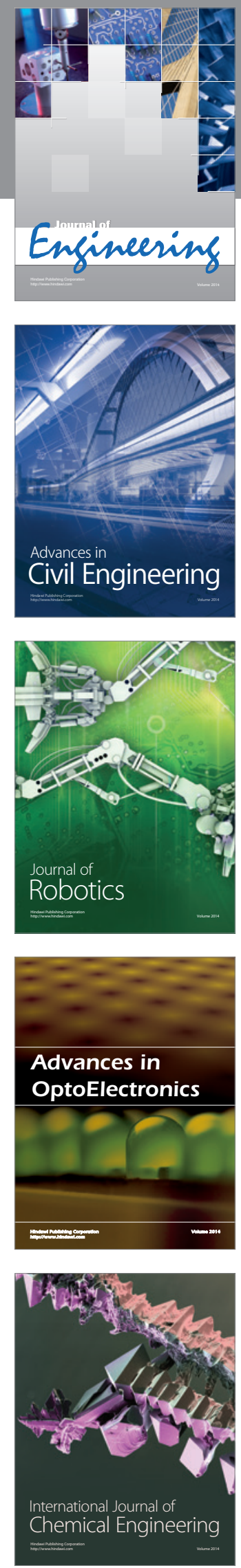

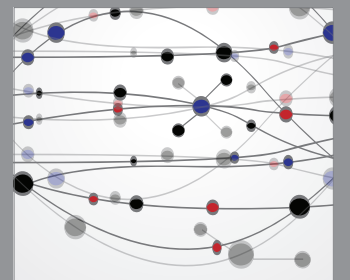

The Scientific World Journal
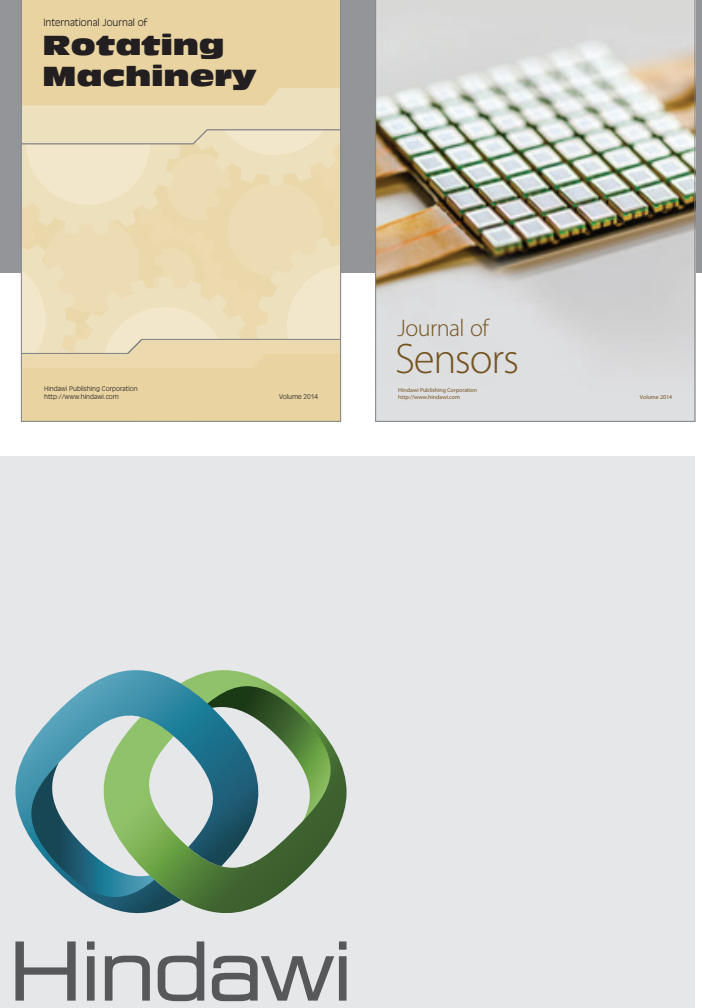

Submit your manuscripts at http://www.hindawi.com
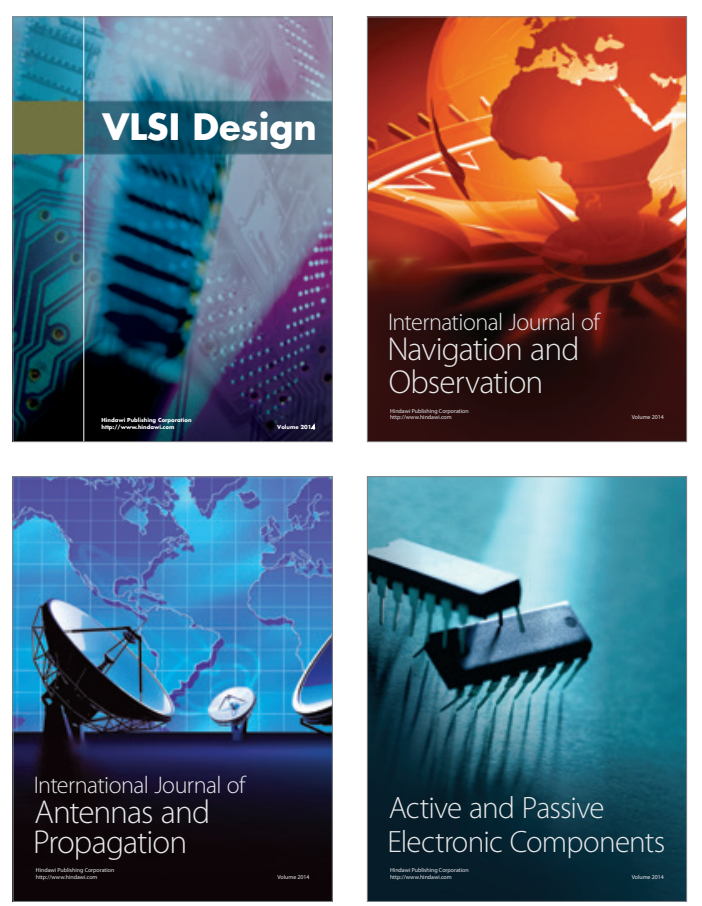
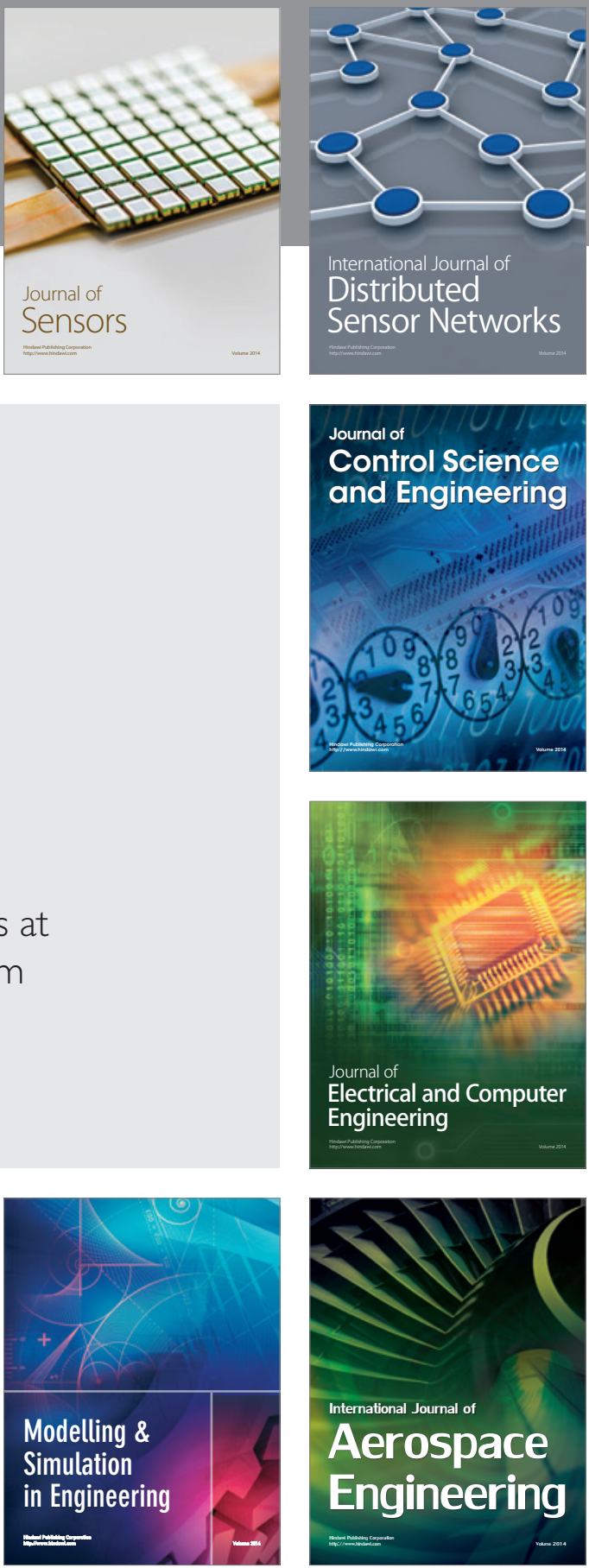

Journal of

Control Science

and Engineering
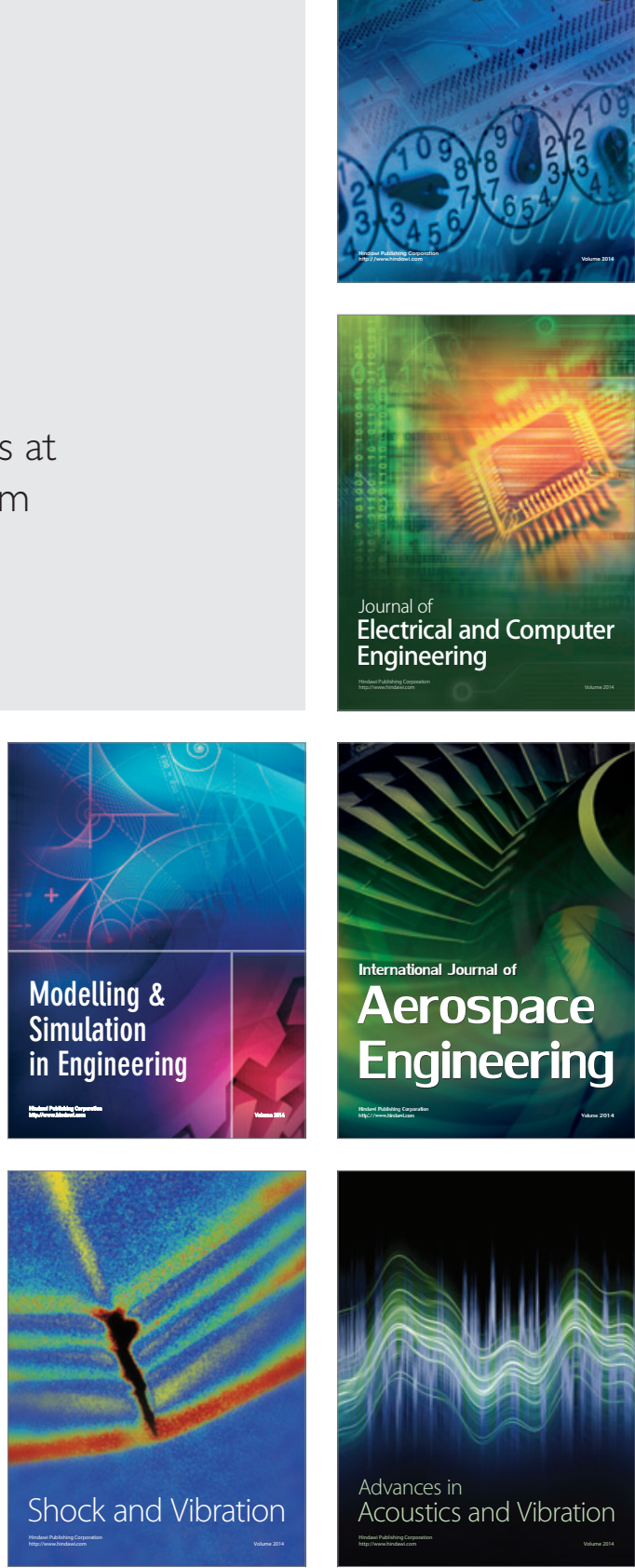